\title{
The effects of water absorption and surface treatment on mechanical properties of epoxy nanocomposite using response surface methodology
}

\author{
Forouzan Gholamian • Sara Ghariban-Lavasani • \\ Mohammad Mehdi Garshasbi • Mahdi Ansari • \\ Farideh Bataghv $\cdot$ Abolghasem Moraveji $\cdot$ Zahra Ranjbar
}

Received: 2 April 2012/ Accepted: 5 February 2013/Published online: 8 March 2013

(C) The Author(s) 2013. This article is published with open access at Springerlink.com

\begin{abstract}
In this study, the dynamic-mechanical properties of fumed silica and silane-treated reinforced epoxy nano-composites were examined; silane-treated specimens demonstrated greater glass transition temperature, modulus, and less moisture absorption. An epoxy composite has been studied under hydrothermal ageing in order to investigate the effect of treatment on dynamical mechanical thermal analysis. The nanocomposites were kept in seawater up to $600 \mathrm{~h}$. The process was then modeled using response surface methodology based on central composite design (CCD). Three models were developed to predict the influence of wet aging parameters on the $\mathrm{Tg}$, modulus, and damping. Accuracy of predicted results was analyzed by the analysis of variance method. The optimum values predicted by the RSM and CCD were $1 \% \mathrm{wt}$ treated fumed silica followed by aging at $60{ }^{\circ} \mathrm{C}$. Multiple correlation coefficients $\left(R^{2}\right)$ of 0.96 were obtained from the regression models for Tg, confirming the good accuracy of developed models.
\end{abstract}

Keywords Epoxy nanocomposites - Hygrothermal ageing - DMTA - Surface treatment $\cdot$ Response surface method

\section{Introduction}

Epoxy resins based on materials are thermosetting polymers widely used for structural applications, adhesives, organic coatings, electrical engineering and

F. Gholamian $(\bowtie) \cdot$ S. Ghariban-Lavasani · M. M. Garshasbi · M. Ansari ·

F. Bataghv · A. Moraveji

Department of Chemistry and Chemical Engineering, Malek Ashtar University of Technical (MUT),

1774-15875 Tehran, Iran

e-mail: shirazfgh@yahoo.com

Z. Ranjbar

Department of Surface Coatings and Corrosion, Institute for Colorants, Paint and Coatings (ICPC),

Tehran, Iran 
aeronautics due to their superior thermal, mechanical, and corrosion-resistance properties [1, 2]. Moreover, they are the most extensively used advanced composite materials in aerospace and advanced automotive applications because of their excellent combination of mechanical properties and corrosion resistance, good adhesion, wetting properties, and dimensional stability with respect to their cost $[3$, 4].

When composites are considered for long applications, it is necessary to know how the materials will behave during the estimated service life [5]. Many researches have investigated the effects of absorbed water on the mechanical behavior of organic matrix composites under humid conditions or during immersion [6, 7]. It is well known that absorbed water can affect the physico-chemical and mechanical properties, and reduction of the $\mathrm{Tg}$ of the material resulting from plasticization and degradation of chemical structure [8,9].

Like all polymeric materials, epoxy resin systems undergo physical ageing phenomena in which the free volume decreases during a period of time because of the tendency of the material to reach the equilibrium condition. The last effect is responsible for increasing the brittleness of the material as a consequence of increasing the density. Physical aging is accelerated and emphasized by plasticization as a result of the water absorption by the resin which increases the mobility of the molecular chain [3].

Water aging was performed to investigate the effect of absorption of seawater in epoxy composites; it can affect the mechanical and chemical properties of the epoxy matrix by plasticization and hydrolysis $[10,11]$. Molecular weight is varied by structural changes such as hydrolysis [12].

One of the interesting aspects of epoxy system is water sorption and water transport which have been considered by various categorization techniques including IR, NIR, UV, NMR, dielectric and dynamic mechanical spectroscopy [13].

Polymer nanocomposites are at the center of attention as a new class of materials which may enhance stiffness, strength, as well as fracture toughness and ductility $[14,15]$. Fine particle size and high specific surface area make the fumed silica the most popular reinforced filler for composites [16]; in spite of their low cost, they have various applications, but the viscosity will be increased by formation of hydrogen bonds between the particles leading to the formation of a threedimensional network in the matrix [17]. Increasing the affinity of the particle surface to the matrix polymer leads to reduced conglomeration behavior [18]. The surface treatment of the particles with organic molecules enhances compatibility and adhesion between the components [19]. Organosilanes in the treated silica surfaces can form chemical bonds between inorganic and organic composite. Recently, these materials which can couple filler to an organic media have attracted lot of attention. Thus, an amino silane can act as a bridge between silica and polymer; thereby those interactions will increase. For silica treatment, amino silane is used regularly [19].

Photo and thermal aging of polymer can be influenced by various aspects such as time of aging, temperature, different environment, and presence of various materials, therefore a suitable experimental design and well-developed models 
can be unique approaches to analyze the aging behavior and to attain the best composites. One convenient and remarkable method is using the statistical models developed by response surface methodology (RSM). RSM is a statistical and mathematical method that was developed by Box et al. [20]. This is fitted to the mathematical model, and its use has been widely adopted to tests on chemometrics. Statistically based design of experiments (DOE) help to increase the speed of the development cycle time, improve reliability, reduce process variability, and increase overall product quality. Using the RSM, one is able to develop the statistical models to evaluate the effect of particular parameters of any process as well as to optimize the conditions for desirable responses. Therefore, in the present study, RSM based on central composite design (CCD) was used to design the experiments and develop new models to determine the optimum mixture for aging process. RSM can be very helpful in designing the experiments and to figure out the aging parameters and their interactions. This technique can be used to investigate the responses of any industrial process and to determine the relation between the response and independent variables by developing a statistical model [21]. This is followed by analyzing the experimental results using the analysis of variance (ANOVA) to determine as to which parameters show the strongest interactions and/or which ones exhibit significant influence on the outputs of the process. The process responses are then represented as statistical developed models. The developed models are then validated by testing at the optimum conditions predicted by RSM [22].

In this paper, in order to design the experiments by a statistical method, firstly the parameters that exhibit significant influence on an aging process such as presence of fumed silica or amino silane should be estimated.

The effect of accelerated hydrothermal ageing on the thermal and mechanical properties was investigated through DMTA and SEM techniques. Accelerated ageing was performed in natural sea water (Persian Gulf) at $60{ }^{\circ} \mathrm{C}$ at different times and the results were compared with neat epoxy composite.

\section{Experimental}

\section{Material}

The epoxy resin, diglycidyl ether of bisphenol F (DGEBF, Epoxy equivalent weight equal to 320), and the Tri Ethylene Tetra Amine (TETA) as hardener (stoichiometric ratio amino hydrogen-to-epoxy 100:15) both is supplied by local compony, Mokarar engineering material (Iran).

Inorganic fillers containing $\mathrm{Fe}_{2} \mathrm{O}_{3}$ (good anticorrosive behavior) and mica (to improve mechanical strength) were also used. $\mathrm{Fe}_{2} \mathrm{O}_{3}$ was provided by Merk $\mathrm{C}$ and mica was provided by Borna Company (Iran). Nanoscale silica particle was AEROSIL ${ }^{\circledR} 200$, fumed silica (specific surface area $=200 \mathrm{~m}^{2} / \mathrm{g}$, Degussa Co.) (http://www.degussa.com, 2011). Aminopropyltrimethoxysilane (APTMS), C9H3NO3Si, $0.98 \%$ in ethanol, was purchased from Merck Co. All other chemical reagents, including ethanol, hydrochloric acid and caustic soda were purchased from Merck Co. All materials were used as received. 
Sample preparation

The amounts of silica and silane were calculated according to a stoichiometric value and hydrolysis ratio as follows:

$$
M=3 \times \mathrm{SsSi} \times \mathrm{mSi} \times \mathrm{M} \text { Silane } \times \mathrm{OH} . \mathrm{No} \times 1,019 / \mathrm{NA}
$$

where $M$ is the amount of silane (in $\mathrm{g}$ ), $\mathrm{SsSi}$ is the surface area of silica, $\mathrm{mSi}$ is the weight of silica, and $M$ Silane is the molecular weight of silane. OH.No is the number of hydroxyl groups per $\mathrm{nm}^{2}$ on silica surface, NA is the Avogadro number and 1,019 is a conversion factor. Silane is poured drop wise. The amounts of materials in the reaction vessel are used from Ref. [18].

An ultrasonic homogenizer is used for all samples at $19,000 \mathrm{rpm}$ for $15 \mathrm{~min}$ to disperse nanoparticles in the solvent. Total reactions last for $3 \mathrm{~h}$. The resulting slurries are centrifuged at $5,000 \mathrm{rpm}$ to remove the untreated particles. Then, in order to increase $\mathrm{pH}$ up to $4,2 \mathrm{cc}$ sodium hydroxide is added to the solution.

\section{Preparation of composites with treated and untreated fumed silica}

Silica particles are ultrasonically dispersed in epoxy resin for $5 \mathrm{~min}$ at amplitude of $20 \%$. A pulser cycle (turning on and off-time ratio of 5:1) is used to control the temperature of the mixture (temperature of the mixture at around $30-40{ }^{\circ} \mathrm{C}$ ).

The resin was mixed with the additives and inorganic fillers $\left(\mathrm{Fe}_{2} \mathrm{O}_{3}\right.$, mica and calcium carbonate) via stirring at room temperature until a homogeneous mixture was formed. Afterwards, a vacuum of $1-5$ mbar is applied for $3 \mathrm{~min}$ to degas the compounds. The resulted mixture was mixed with the hardener by stirring [the ratio of epoxy and amine groups is kept constant (100:15)]. Eight composites are formulated, containing three different amounts of fumed silica $(0,1$, and $2 \mathrm{wt} \%)$ and amino silane (as is shown in Table 1).

Thermal analysis was performed using a Mettler Toledo (TGNSDTA851) model under nitrogen flow at a heating rate of $10{ }^{\circ} \mathrm{C} / \mathrm{min}$.

\section{Weathering experiment conditions}

The fully cured (at $60{ }^{\circ} \mathrm{C}$ for $24 \mathrm{~h}$ ) composites were immersed in natural sea water (Persian Gulf) at $60{ }^{\circ} \mathrm{C}$ at different time intervals. The sea water was filtered to remove sedimented particles. To do so, the film thickness of composites for hydrothermal aging was $2 \mathrm{~mm}$. Gravimetric analysis was conducted by weighing

Table 1 Selected levels of variables for central composite design (coded value)

\begin{tabular}{lllllll}
\hline Name & \multicolumn{3}{l}{ Coded value } & & \\
\cline { 3 - 6 } & & $-\alpha$ & -1 & 0 & +1 & $+\alpha$ \\
\hline$A$ & \% Wt fume silica & 0 & 0.4 & 1 & 1.6 & 2 \\
$B$ & \% Wt APTMS & 0 & 0.4 & 1 & 1.6 & 2 \\
$C$ & Time of aging (h) & 0 & 122 & 300 & 478 & 600 \\
\hline
\end{tabular}


with a resolution of $0.0001 \mathrm{~g}$ to evaluate moisture content, which was expressed as a percentage of the composite's initial dry mass. Samples were wiped with paper towels and placed in the oven for $12 \mathrm{~h}\left(\right.$ at $\left.40^{\circ}\right)$ before weighing to dry the surfaces. The mass $M$ of each sample at time is expressed as (2).

$$
\text { Moisture content } \%=\frac{M_{\mathrm{t}}-M_{\mathrm{dry}}}{M_{\mathrm{dry}}} \times 100
$$

where $M_{\mathrm{t}}$ is the measured mass at equilibrium moisture content ( $\mathrm{g}$ ) and $M_{\mathrm{dry}}$ is the dry mass $(\mathrm{g})$ :

Dynamic mechanical thermal analysis (DMTA) and scanning electron microscopy (SEM)

The formulated composites are casted in silicon molds and cured in the oven for DMTA test $\left(60{ }^{\circ} \mathrm{C}, 24 \mathrm{~h}\right)$; then, the tests are conducted after 7 days. DMTA has been performed by a Perkin Elmer DMTA instrument. Experiments are carried out in a temperature range between 25 and $150{ }^{\circ} \mathrm{C}$, as well as at a heating rate of $2{ }^{\circ} \mathrm{C} /$ min under a flow of nitrogen. The frequency is set to $1 \mathrm{~Hz}$ (isochronal measurement) and maximum strain amplitude $0.02 \%$. All experiments are performed on a $25 \times 10 \mathrm{~mm}$ silicon rectangular sheet. Visco-elastic properties such as modulus and mechanical loss tangent $(\tan \delta)$ are reported as a function of temperature [22]. The degree of dispersion of the filler within the matrix was analyzed by SEM investigations. The SEM analysis was carried out with VEGA, TESCAN, Czech Republic.

Modeling by response surface methodology (RSM)

The aim of modeling of aging properties by RSM was to find the optimal combination to attain the maximum water aging resistant trace. The parameters for modeling was selected as aging-time, untreated and treated nano silica. For each parameter, five values were considered in the model. The investigated parameters and their levels are given in Table 1 . In this table, $\alpha$ refers to the position of the axial point of the cubic in central composite design (CCD). Functional relationships between the independent variables (aging-time, fumed silica and aminosilane amount) and dependent variables (Tg, damping and modulus) were determined using the multiple regression technique having the following format:

$$
\begin{aligned}
& Y=\varepsilon 0+\sum_{i=1}^{n} \varepsilon i X i+\sum_{i=1}^{n-1} \sum_{j=i+1}^{n} \varepsilon_{i j} X_{i} X_{j}+\sum_{i=1}^{n} \varepsilon_{i i} X_{i}^{2} \\
& Y=\varepsilon_{0}+\sum_{i=1}^{n} \varepsilon_{i} X_{i}+\sum_{i=1}^{n-1} \sum_{j=i+1}^{n} \varepsilon_{i j} X_{i} X_{j}+\sum_{i=1}^{n} \varepsilon_{i i} X_{i}^{2}
\end{aligned}
$$

where $\varepsilon_{0}, \varepsilon_{i}, \varepsilon_{i j}$ and $\varepsilon_{i i}$ are coefficients, $X_{i}$ and $X_{j}$ are the independent variables, $Y$ (as a dependant variable) is the response and $n$ is the number of independent variables. The regression equations are then developed and used to describe the effects of 
controlling parameters on the responses, determine the relationships between variables, and to represent the total effect of all variables. To develop a regression model, the experimental variables were coded according to Eq. 5

$$
x_{i}=\frac{X_{i}-X_{0}}{\Delta X_{i}}
$$

where $x_{i}$ and $X_{i}$ are, respectively, the coded and actual values of the experimental variable; $X_{0}$ is the actual value of the experimental variable at the central point; and $\Delta X_{i}$ is the step change value. In the present study, we selected central composite design for three of the variables; in this way, 17 DMTA tests were carried out for different composites. The most important factors which were controlled in this study were:

- amount of fumed silica $(A)$,

- amount of aminopropyltrimethoxysilane (APTMS) (B),

- time of aging $(C)$.

In this work, experimental design was performed using Design-Expert 7 computer software (trial version, Stat-Ease Inc., USA) to study the aging behavior of epoxy nanocomposites and determine the most significant variables that can affect the ageing.

\section{Results and discussion}

Treated fumed silica

TGA analysis (Fig. 1) was conducted on the product to indicate that the treatment of silica surface has taken place. The TG thermogram for treated silica shows three stages of weight loss steps with total weight loss. In the first step, weight loss occurs at $64.6{ }^{\circ} \mathrm{C}$. In the second step, weight loss of approximately $6.44 \%$ at temperature of $101.96{ }^{\circ} \mathrm{C}$ was attributed to the release of adsorbed water and volatiles such as alcohol, while the weight loss in the temperature range $200-400{ }^{\circ} \mathrm{C}$ results from the silanol condensate groups and the decomposition of the grafted APTMS molecule. The decomposition of aminopropyl groups occurs slowly at 200-400 ${ }^{\circ} \mathrm{C}$, followed by a rapid degradation above $4,008{ }^{\circ} \mathrm{C}$. The decomposition of amino silane leads to the formation of ammonia, ethylene, hydrazine and methane which is in good agreement with the literature [19].

\section{Dynamic mechanical analysis}

Dynamic mechanical properties are the mechanical properties of materials as they are deformed under periodic or varying forces. In the linear region, the applied force and the resulting deformation both vary sinusoidally with time. The importance of determining the dynamic mechanical properties of polymers and composites can be illustrated by outlining the various aspects of material structure or behavior to which 


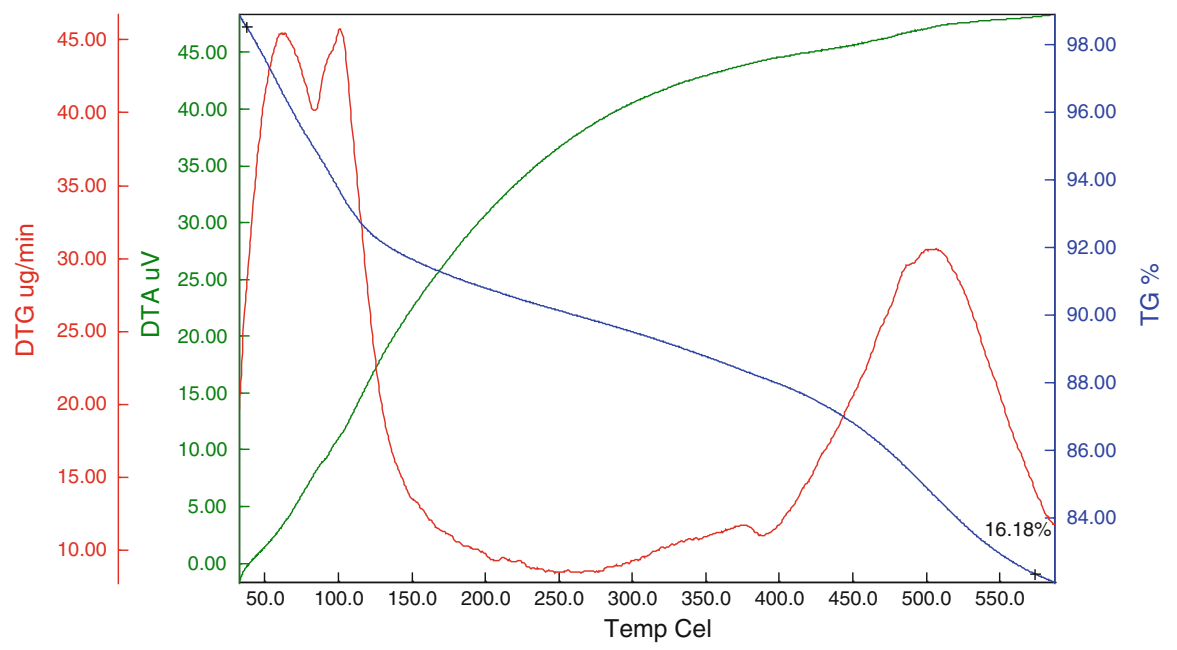

Fig. 1 TGA of treated fumed silica

the dynamic properties are related and the range of applications for which dynamic data are directly relevant. In the present study, the $\tan \delta$ curve as a function of temperature (obtained from a temperature sweep test) was chosen for $\mathrm{Tg}$ determination because the $\mathrm{Tg}$ is found most accurately at the peak of the $\tan \delta$ curve. In addition, the $\tan \delta$ curve is more sensitive to property changes at the molecular level of the material [23]. Properties such as glass transition, damping, and modulus of these samples were investigated before and after the samples were soaked in sea water at an aging condition.

The glass transition temperature of the neat epoxy composite was $76.2{ }^{\circ} \mathrm{C}$ (Fig. 3). In the presence of the untreated fumed silica, the $\mathrm{Tg}$ decreases by increasing the percentage of nanoparticle. At $1 \% \mathrm{wt}$, the glass transition decreased by nearly $4.8^{\circ} \mathrm{C}$. Water molecules adsorbed on the surface of the nanoparticles may cause decrease in composite's Tg containing untreated fumed silica. The untreated nano silica particles used in this study show a remarkably hydrophilic behavior; they carried a significant amount of water into the epoxy matrix, which can decrease the glass transition temperature significantly. The surface of the untreated fumed silica contains a lot of hydroxyl groups, causing extremely hydrophilic behavior. So it could absorb water easily, linked to the particles via hydrogen bonds [24].

The silane-treated particles significantly affect the glass transition temperature, the Tg will increase $8.2{ }^{\circ} \mathrm{C}( \pm 0.5)$ for $1 \%$ wt fumed silica treated with $1 \%$ silane; also for $2 \%$ wt fumed silica the Tg will increase $12.7{ }^{\circ} \mathrm{C}( \pm 0.5)$ (for $1 \% \mathrm{wt}$ amino silane) and $18.1{ }^{\circ} \mathrm{C}( \pm 0.5)$ (for $2 \%$ wt silane). It could be related to the formation of covalent bond between silica surface and the matrix to form chemical bonds [13]. Increasing of $\mathrm{Tg}$ and decreasing of the free volume may be related to crosslinking of polymer. It required more rotation energy because of more specific volume and mobility of the molecular motion. It is evidence of the successful treatment of the silica surface [25]. 
SEM analysis was performed on the surfaces of the nanocomposites (Fig. 2). It could be seen in Fig. 2a, c, the fumed silica was partially agglomerated which indicates the poor dispersion and weak interfacial bonding between fumed silica and the epoxy matrix. However, in the case of the treated-fumed silica/epoxy nanocomposites (Fig. 2d), the particles were dispersed better and the amount of wetted nano silica increased compared to the untreated particles. These results indicate that the surface treatment could help dispersion and interfacial bonding between the nano silica and the epoxy matrix. A strong agglomeration phenomenon was observed for the $4 \%$ wt untreated fumed silica (Fig. 2c).

SEM micrograph (Fig. 2b) shows that silica nanoparticles were well dispersed, however, Fig. 2c shows that silica particles are spherical in shape and agglomerates. It may show that the silica particles are well bonded in the epoxy matrix but the particles have a strong tendency to agglomerate due to weak interaction between the

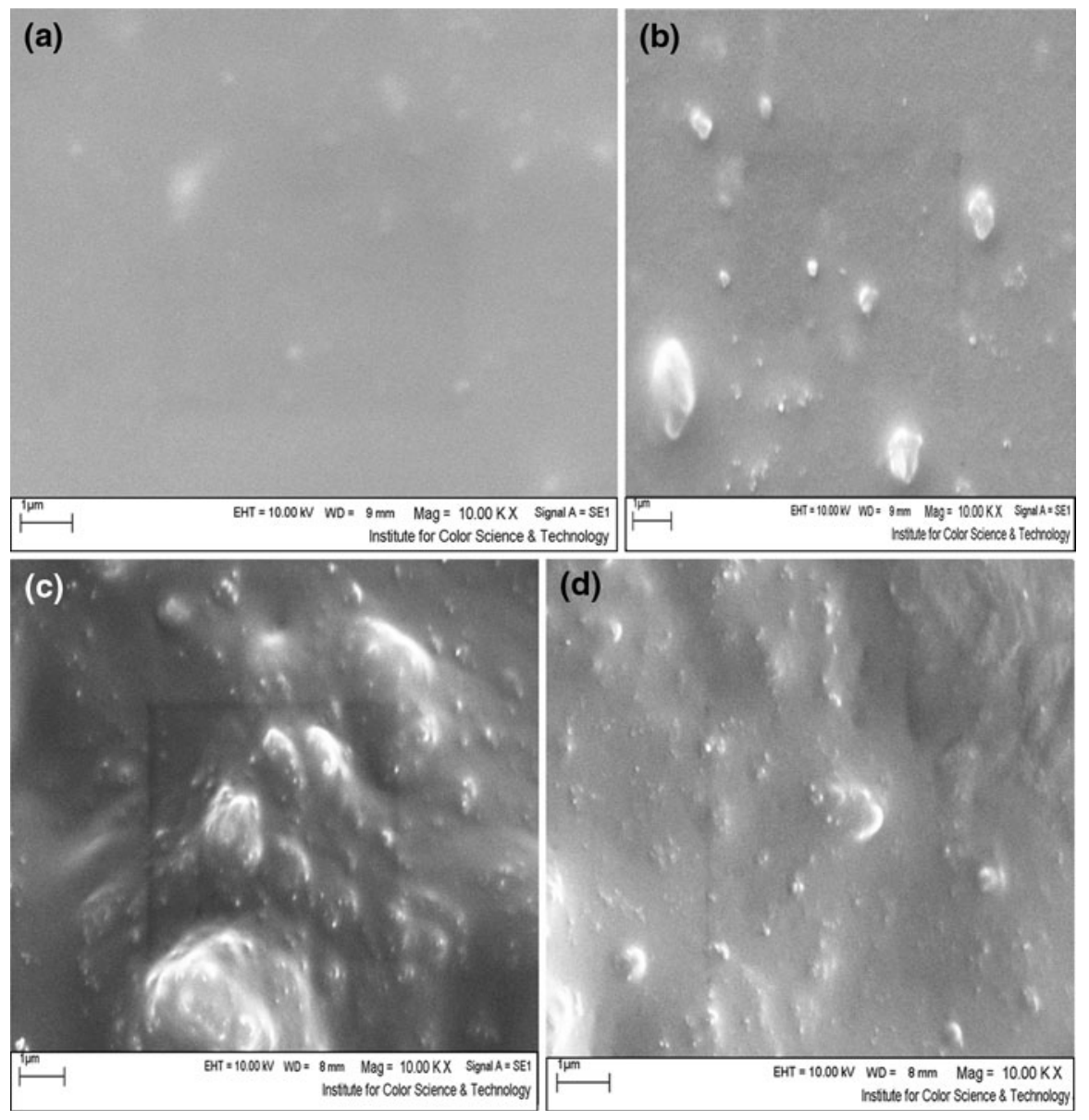

Fig. 2 SEM micrographs of not aged surfaces. a $0 \%$ wt fumed silica; b $2 \%$ wt; c $4 \%$ wt; d treated $2 \%$ wt 
two phases. It shows that the particles dispersion into the epoxy matrix is not homogeneous. The agglomerate is a result of the formation of a silica-silica aggregated structure due to hydrogen bonding.

The influence of hydrothermal ageing on dynamic mechanical and morphology properties of nanocomposites

Sea water can change the physical and mechanical properties of the nanocomposite because of absorbing and diffusing through the film. Besides, the existence of hydrogen-bonding sites is a main factor in the polymer-water affinity along the polymer chains, which produces attractive forces between the polymer and the water molecules [13].

As could be seen in Fig. 3a, b, Tg decreases from 76.2 to $68.5^{\circ} \mathrm{C}$ for neat epoxy composite. Decreasing of the glass transition temperature and modulus, and increasing of damping could be related to plasticization by water and wider distributions of molecular weights of composite during environmental exposure especially at the elevated temperature $[3,9,26]$. As the temperature increases, water penetrated into the cross-linked domain (less plasticized phase) where water hardly penetrated at room temperature aging.

In treated nanocomposite, silane molecule could relieve strained flexible $\mathrm{Si}-\mathrm{O}-\mathrm{Si}$ bonds and might increase the resistance of the interfacial $\mathrm{Si}-\mathrm{O}-\mathrm{Si}$ bonds to water attack [27]. It could lessen the amount of absorbed water, furthermore, the treated silica particles interface had considerably more resistance to crack growth than the untreated fumed silica.

Water is a present compound that can be absorbed into and diffused through epoxy-based composite. The primary mechanism for moisture absorption in epoxy composite is surface absorption which can diffuse through the resin phase [5]. In this work, the moisture absorption of fumed silica/epoxy composites was calculated using the weights of the specimens before and after moisture absorption by Eq. (1). Table 2 shows the seawater contents for all samples of epoxy nanocomposite and time of immersion in water. The results showed water diffusion increased significantly for untreated samples, since treated nanocomposites showed lower water uptake due to hydrogen bonds between the particles leading to the formation of a three-dimensional network.

One relaxation peak can be observed for treated composite ( $\tan \delta / T$ curves) (Fig. 3 ), but a shoulder can be observed (in 190-200 ${ }^{\circ} \mathrm{C}$ ) for untreated composite (especially for $1 \%$ fumed silica). It may be related to treatment, which can decline water diffusion, and indicates a more uniform network.

\section{Optimization by RSM and CCD}

Aging of fumed silica/epoxy composites in sea water at different time or in different combination with sustained load is detrimental to their thermal, physical, and mechanical properties. In the present study, an aging condition was applied to fumed silica/epoxy composite. Their changes of epoxy composites were followed by DMA measurements. The following models, i.e. Eqs. (6) and (7), were then 

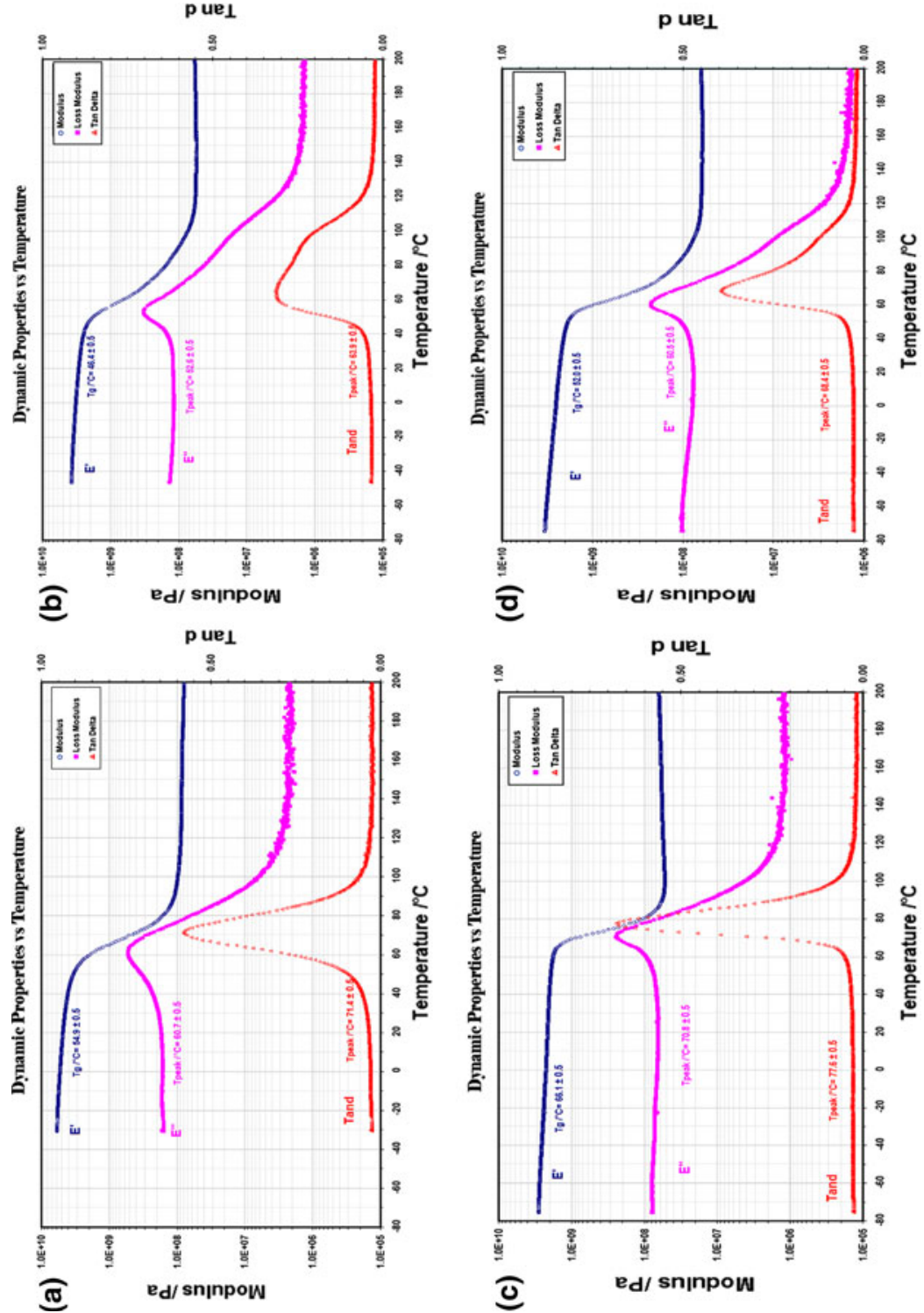

Fig. 3 A comparison of plots of tan delta, loss factor, and storage modulus vs. temperature for different percentages of fumed silica and amino silane (fumed silica:amino silane) aged in sea water at $60^{\circ}$ at different times a 0:0/unaged, b 0:0 aged for $500 \mathrm{~h}$, c 1:0/unaged, d 1:0 aged for $250 \mathrm{~h}$, e 1:1/unaged, f 1:1, aged for $250 \mathrm{~h}, \mathbf{g} 2: 1 /$ unaged, $\mathbf{h} 2: 1$ aged for $250 \mathrm{~h}$ 

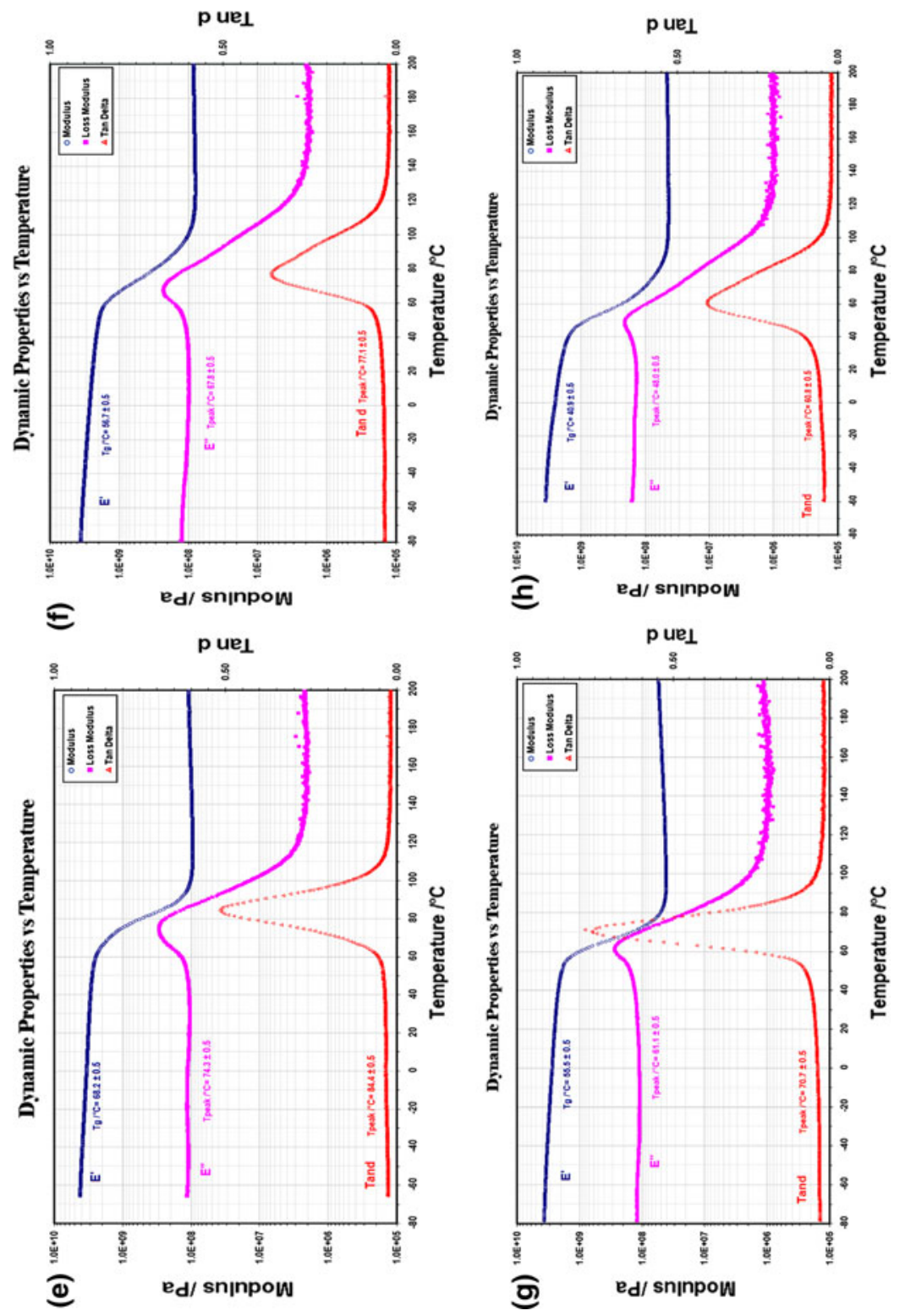

Fig. 3 continued 
Table 2 Moisture content of different composites

\begin{tabular}{lll}
\hline Name & Time of aging & Moisture content (\%) \\
\hline Neat epoxy composite & 500 & $2.120 \pm 0.001$ \\
UN/composite 1\% Wt & 250 & $1.171 \pm 0.001$ \\
UN/composite 2\% Wt & 500 & $2.080 \pm 0.001$ \\
UN/composite 4\% Wt & 600 & $3.670 \pm 0.001$ \\
T 1\%/composite 1\% Wt & 250 & $0.500 \pm 0.001$ \\
T 1\%/composite 1\% Wt & 600 & $0.550 \pm 0.001$ \\
T 1\%/composite 2\% Wt & 250 & $0.340 \pm 0.001$ \\
T 2\%/composite 1\% Wt & 250 & $0.780 \pm 0.001$ \\
T 2\%/composite 2\% Wt & 600 & $0.650 \pm 0.001$ \\
\hline
\end{tabular}

developed, respectively, for $\mathrm{Tg}$, modulus $(M)$, and damping $(D)$ using the regression coefficient summarized in Table 3 . Where $A, B$ and $C$ are, respectively, the coded values for, amount of fumed silica (\% wt), amino silane (\% wt) and aging-time (h), also $R_{1}$ is Tg from $\tan \delta, R 2$ is modulus at $140{ }^{\circ} \mathrm{C}(\mathrm{M})$, and $\mathrm{R} 3$ is damping (length of half height) (Tables 4, 5, 6, 7).

Final equation in terms of coded factors $\mathrm{Tg}$ :

Table 3 Central composite design and experimental results

\begin{tabular}{lclllllll}
\hline Std & Run & Block 1 & Factor 1 & Factor 2 & Factor 3 & R1 & R2 & R3 \\
\hline 4 & 1 & Block 1 & 1.6 & 1.6 & 122 & 77 & 5.1 & 21.5 \\
10 & 2 & Block 1 & 2 & 1 & 300 & 64.9 & 1.9 & 31.4 \\
1 & 3 & Block 1 & 0.4 & 0.4 & 122 & 73.7 & 4.6 & 18.4 \\
3 & 4 & Block 1 & 0.4 & 1.6 & 122 & 55.9 & 2.2 & 32 \\
17 & 5 & Block 1 & 1 & 1 & 300 & 75 & 8.8 & 36.6 \\
11 & 6 & Block 1 & 1 & 0 & 300 & 76 & 8.1 & 36 \\
6 & 7 & Block 1 & 1.6 & 0.4 & 478 & 63.9 & 4.3 & 32 \\
14 & 8 & Block 1 & 1 & 1 & 600 & 74.4 & 10.1 & 30.4 \\
5 & 9 & Block 1 & 0.4 & 0.4 & 478 & 67 & 2.98 & 43 \\
16 & 10 & Block 1 & 1 & 1 & 300 & 76.3 & 8.2 & 35.9 \\
2 & 11 & Block 1 & 1.6 & 0.4 & 122 & 59.1 & 5.4 & 22 \\
9 & 12 & Block 1 & 0 & 1 & 300 & 49.8 & 0.2 & 49.1 \\
8 & 13 & Block 1 & 1.6 & 1.6 & 478 & 76.1 & 7.1 & 22.4 \\
13 & 14 & Block 1 & 1 & 1 & 0 & 80.8 & 9.8 & 9.1 \\
15 & 15 & Block 1 & 1 & 1 & 300 & 75.5 & 8 & 36.3 \\
12 & 16 & Block 1 & 1 & 2 & 300 & 58.4 & 4.1 & 32.3 \\
7 & 17 & Block 1 & 0.4 & 1.6 & 478 & 43.4 & 3.8 & 47.2 \\
\hline
\end{tabular}


Table 4 ANOVA of RSM regression analysis for modulus and $\mathrm{Tg}$

\begin{tabular}{|c|c|c|c|c|c|c|c|c|c|c|}
\hline \multirow[b]{2}{*}{ Source } & \multicolumn{5}{|c|}{ Modulus } & \multicolumn{5}{|c|}{ Damping } \\
\hline & SS & DF & MS & $\mathrm{F}-\mathrm{V}$ & $\mathrm{P}-\mathrm{V}$ & SS & $\mathrm{DF}$ & MS & $\mathrm{F}-\mathrm{V}$ & $\mathrm{P}-\mathrm{V}$ \\
\hline Model & 128.05 & 9 & 14.23 & 9.2 & 0.0040 & 93.74 & 9 & 189.6 & 67.88 & $<0.0001$ \\
\hline Residual & 10.83 & 7 & & & & 17.38 & 7 & & & \\
\hline Total & 138.88 & 16 & & & & 111.12 & 16 & & & \\
\hline
\end{tabular}

Table 5 ANOVA of RSM regression analysis for $\mathrm{Tg}$

\begin{tabular}{llllll}
\hline Source & \multicolumn{1}{l}{ Tg } & & MS & F-V & P-V \\
\cline { 2 - 5 } & SS & DF & & & \\
\hline Model & $1,830.43$ & 9 & 203.38 & 21.2 & 0.0003 \\
Residual & 67.14 & 7 & 9.59 & \\
Total & 1,897 & 16 & & & \\
\hline
\end{tabular}

Table 6 Analyses of the results of central composite design for Tg and modulus

\begin{tabular}{|c|c|c|c|c|c|c|}
\hline & \multicolumn{3}{|l|}{$\mathrm{Tg}$} & \multicolumn{3}{|l|}{ Modulus } \\
\hline & Mean square & $f$ value & $p$ value & Mean square & $f$ value & $p$ value \\
\hline$A$ & 203.38 & 28.82 & 0.0010 & 9.15 & 5.92 & 0.0453 \\
\hline$B$ & 276.45 & 12.76 & 0.0091 & 2.47 & 1.60 & 0.2469 \\
\hline$C$ & 122.39 & 5.2 & 0.0566 & 0.14 & 0.091 & 0.7720 \\
\hline $\mathrm{AB}$ & 49.87 & 66.63 & $<0.0001$ & 2.08 & 1.35 & 0.2841 \\
\hline $\mathrm{AC}$ & 639.03 & 6.95 & 0.0036 & 0.11 & 0.068 & 0.8012 \\
\hline $\mathrm{BC}$ & 16.53 & 1.72 & 0.2306 & 4.99 & 3.23 & 0.1154 \\
\hline$A^{2}$ & 548.38 & 57.18 & 0.0001 & 89.68 & 57.98 & 0.0001 \\
\hline$B^{2}$ & 137.75 & 14.36 & 0.0068 & 12.08 & 7.81 & 0.0267 \\
\hline$C^{2}$ & 0.35 & 0.036 & 0.854 & 2.10 & 0.78 & 0.4077 \\
\hline
\end{tabular}

Table 7 Analyses of the results of central composite design for damping

\begin{tabular}{lrrr}
\hline \multicolumn{2}{c}{ Damping } & & \\
\cline { 2 - 4 } & Mean square & $f$ value & $p$ value \\
\hline$A$ & 384.54 & 137.67 & $<0.0001$ \\
$B$ & 0.16 & 0.057 & 0.8178 \\
$C$ & 584.16 & 196.25 & $<0.0001$ \\
$\mathrm{AB}$ & 97.30 & 34.84 & 0.0006 \\
$\mathrm{AC}$ & 104.40 & 37.34 & 0.0005 \\
$\mathrm{BC}$ & 42.78 & 15.32 & 0.0058 \\
$A^{2}$ & 14.28 & 5.11 & 0.0583 \\
$B^{2}$ & 11.99 & 4.29 & 0.0770 \\
$C^{2}$ & 422.58 & 151.30 & $<0.0001$ \\
\hline
\end{tabular}



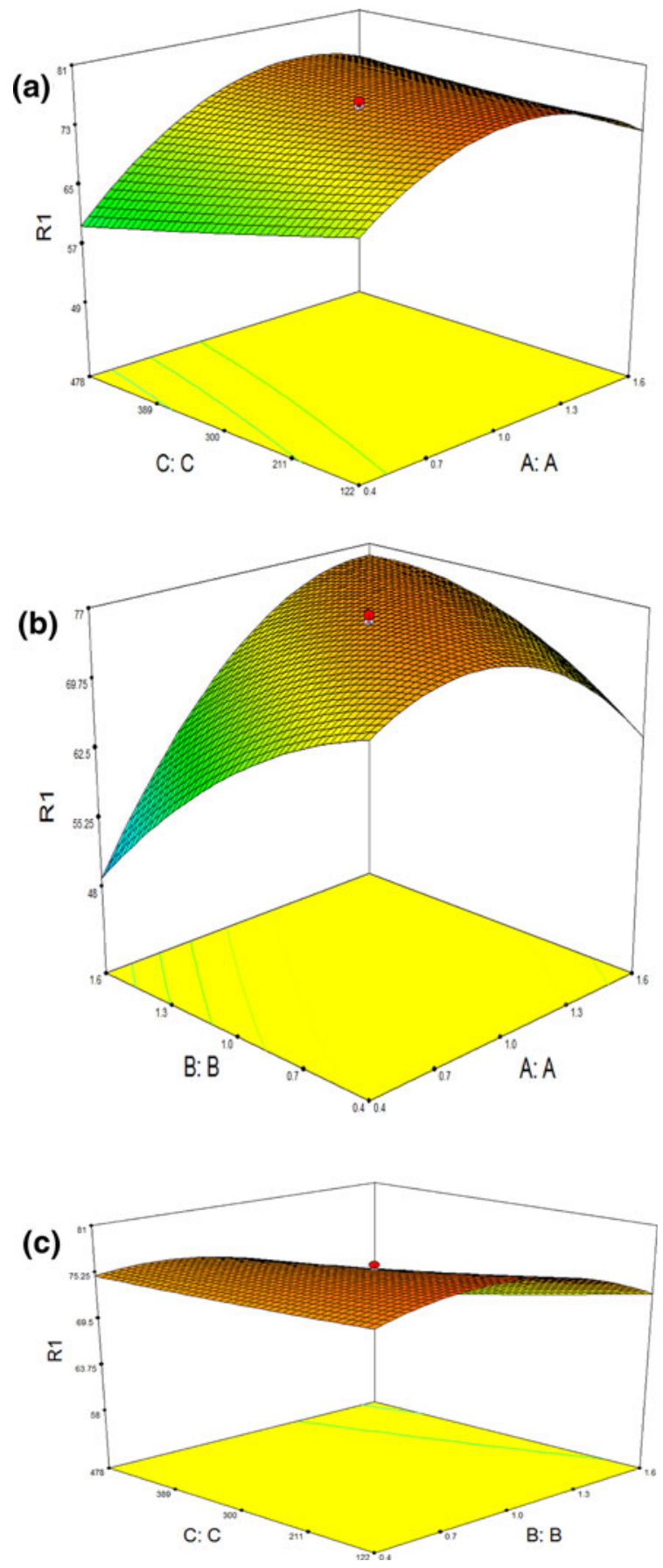

Fig. 4 Contour plots of the $\mathrm{Tg}$, for the interaction between a time $(C)$ and fumed silica $(C)$, b fumed silica $(A)$ and amino silane $(B)$, and $\mathbf{c}$ time $(C)$ and amino silane $(B)$ 


$$
\begin{aligned}
\operatorname{Tg}= & +75.75+4.50 A-2.99 B-1.91 C+8.94 A B+2.89 A C \\
& -1.44 B C-6.97 A^{2}-3.50 B^{2}+0.18 C^{2}
\end{aligned}
$$

Final equation in terms of actual factors $\mathrm{Tg}$ :

$$
\begin{aligned}
\mathrm{Tg}= & 76.699+13.57 A-6.487-0.02 C+25.279 A B+0.02 A C \\
& -0.013 B C-19.72 A^{2}-9.88 B^{2}+(5.5342 E-006) C^{2}
\end{aligned}
$$

Final equation in terms of coded factors for modulus:

$$
\begin{aligned}
M= & 8.40+0.82 A-0.43 B+0.1 C+0.51 A B+0.11 A C+0.79 B C \\
& -2.81 A^{2}-1.03 B^{2}+0.33 C^{2}
\end{aligned}
$$

Final equation in terms of actual factors for modulus:

$$
\begin{aligned}
M= & 1.597+15.56 A+1.46 B-0.014 C+1.44 A B+(1.08 E-003) A C \\
& +(7.45 E-003 B C)-7.977 A^{2}-2.927 B^{2}+1.025 E-005 C^{2}
\end{aligned}
$$

Final equation in terms of coded factors damping:

$$
\begin{aligned}
D= & 36.35-5.31 A+0.11 B+6.34 C-3.49 A B-3.61 A C-2.31 B C \\
& +1.13 A^{2}-1.03 B^{2}-6.12 C^{2}
\end{aligned}
$$

There are so-called $f$ values and $P$ values. The higher amounts of the $f$ value and lower amounts of the $P$ value can imply more significant coefficient values of "Prob $>\mathrm{F}$ " less than 0.0500 indicate model terms are significant. For Tg, A, B, AC, $\mathrm{AB}, A^{2}, B^{2}$ are significant model terms. Therefore, they are considered as significant variables for each response of $\mathrm{Tg}$. Besides, it is necessary to test the accuracy of the model using analysis of variance (ANOVA) method. ANOVA is applied to statistically analyze the performance of the developed models by the Fisher's $F$ test (overall model significance). One way to do this is determining the value of $R^{2}$. With respect to the models developed for $\mathrm{Tg}$, the $R^{2}$ was 0.9648 . This indicates that the model can explain $96 \%$ variation in the response for Tg. As already mentioned, the regression models can be used to predict the effects of processing parameters as well as to optimize them. As it is observed, there is a very good agreement between the experimental and predicted amounts.

In damping model $A, C, \mathrm{AB}, \mathrm{AC}, \mathrm{BC}$ and $C^{2}$ are significant model terms, $\mathrm{AB}$ (interaction of fumed silica and amino silane) has minus coefficient, it is shown that damping and molecular distribution will decrease with treatment; also time $(C)$ has the biggest coefficient (Eq. 10) that confirms aging behavior by lasting time and this effect will reduce in the presence of nanoparticles or silane.

This can be interpreted in terms of more mobility restriction, means of forming a so-named rigid amorphous phase, which is not able or less able to perform the glass transition. The evolution of the loss factor has not only one reason but during the radical-based oxidative ageing two competitive processes take place: chain scission and intermolecular chain radical combination thereby forming crosslinking. A decrease of $\tan (\delta)$ causes formation of more cross links and therefore resulting in more rigid three-dimensional network. An increase of tan $(\delta)$ characterizes an 

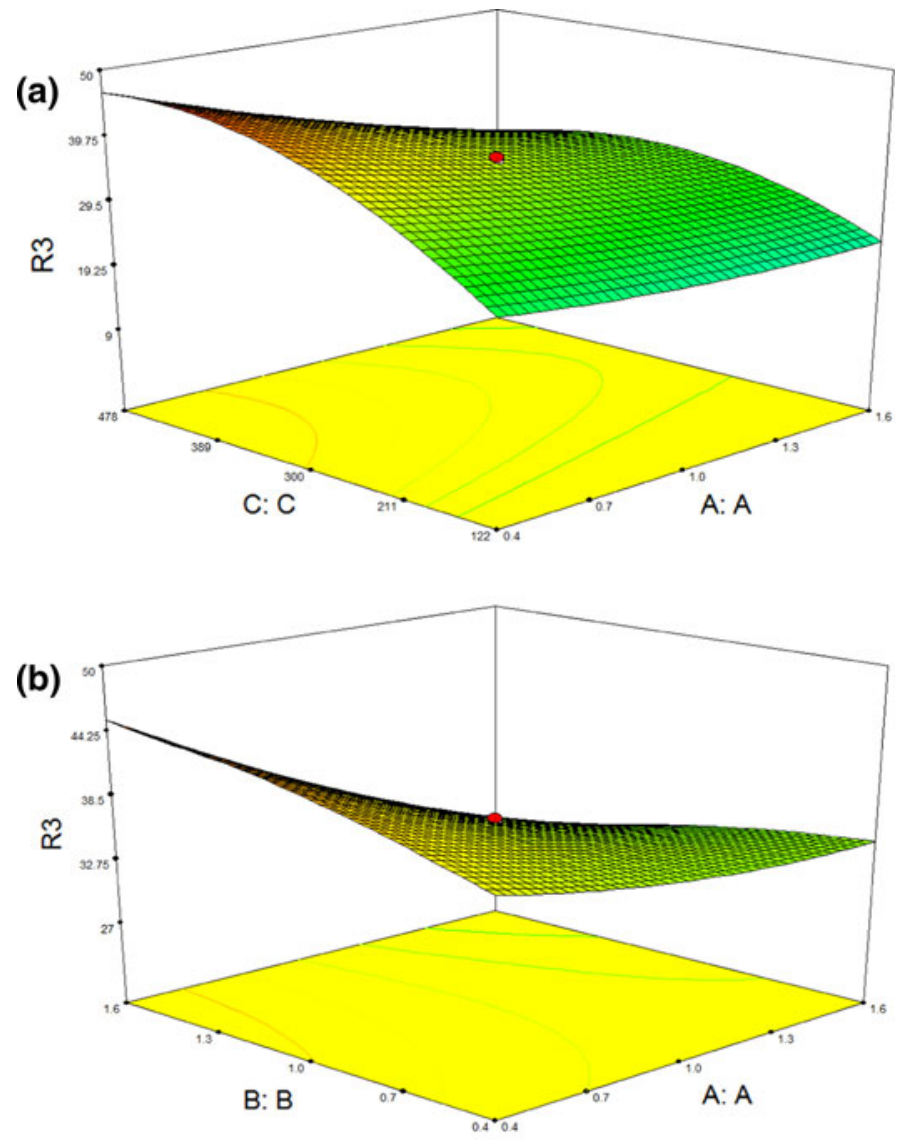

(c)

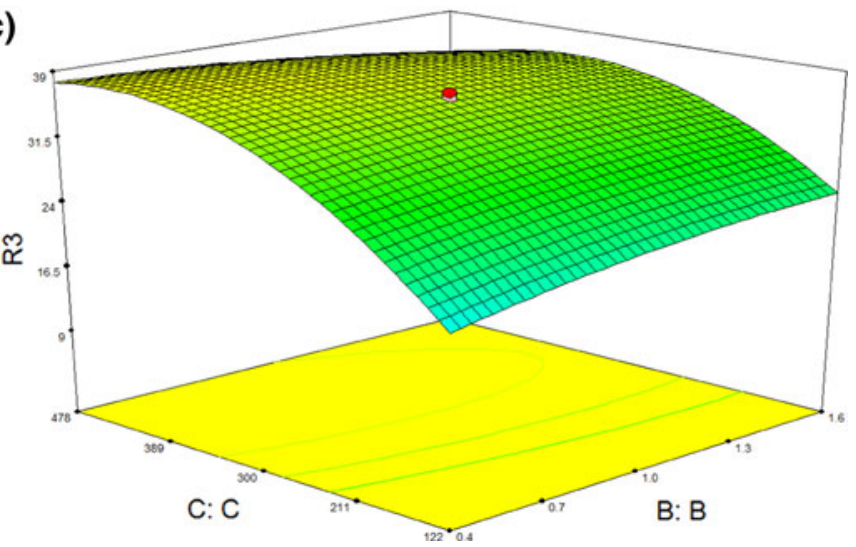

Fig. 5 Contour plots of the damping, for the interaction between a time $(C)$ and fumed silica $(C)$, b fumed silica $(A)$ and amino-silane $(B)$, and $\mathbf{c}$ time $(C)$ and amino silane $(B)$ 
increase of the macromolecular mobility, which can be caused by chain scission [28] and/or by dewetting [29].

Consequently, the developed models for Tg, damping, and modulus can be used successfully to optimize the aging process and its variables. The effects of three factors as well as their interactive effects on the responses are shown in Figs. 4 and 5. From these figures, the effect of each variable and their interactive effects can be studied. The shapes of the contour plots are then used to interpret the interactions between the variables. If the contour plots are circular, it means that the interactions between the variables are not significant, i.e. having no notable interaction. By contrast, elliptical plots imply that the interactions between variables are important, i.e. exhibiting strong interaction [30].

The aim of response surface optimization is to find a desirable composite. This position could be a maximum, a minimum, or an area where the response is stable over a range of factors. The main goal of this study was to develop a model process for optimizing the experimental parameters through preparing to obtain a nanocomposite with the best wet aging behavior. The importance of the factors and their effects (either positive or negative) can be explained by the magnitude and sign of the coefficients of coded equation (Eq. 6, 8, and 10). The Tg's model coefficient of factor $A \times B$ (8.94) is the biggest coefficient which shows the importance of treating fumed silica rather than untreated nanocomposites or silane alone.

Therefore, using these plots one can determine the optimal combination of $\mathrm{Tg}$ variables. Each response plot offers an infinite number of combinations of two variables when the third one is kept at its respective zero level. For example, referring to three-dimensional surface plots in Fig. $4 \mathrm{~b}$, when the time $(C)$ is kept at its zero level, i.e. $300 \mathrm{~h}$, the $\mathrm{Tg}$ is increased with increasing amino silane and fumed silica $(A)$ up to $1 \% \mathrm{wt}$ fumed silica that is treated with $1 \% \mathrm{wt}$ amino silane. This happens when the $\mathrm{Tg}$ increases from 49 to $79{ }^{\circ} \mathrm{C}$ and fumed silica increases from 0 to $1 \%$, corresponding to the values of $B(1 \% \mathrm{wt})$.

\section{Conclusions}

In this work a nanocomposite was treated with different concentrations of amino silane and thermally cured. The characterization was performed by DMTA, DSC and gravimetric measurements.

DMTA of cured treated samples showed an increase of the glass transition temperature of about $8.2^{\circ} \mathrm{C}$ and an increase of the systems compared to the neat resin.

Different combinations of composites were immersed in seawater from the Persian Gulf for up to $600 \mathrm{~h}$ at $60{ }^{\circ} \mathrm{C}$. Samples were tested in tension at durations up to $600 \mathrm{~h}$. Absorption of seawater increased gradually with immersion time and decreased the Tg of the nanocomposites as water acts as plasticizer. Decreasing of the Tg of epoxy composites treated with amino silane is less than other samples due to the increase in cross-link density. The higher crosslink density means more epoxy ring open and so more $-\mathrm{OH}$ groups formed. Also sea water aging influences the 
lowering of $\mathrm{Tg}$ as well as the phase separation in fumed epoxy composite samples due to the plasticization effect. The effect of plasticization was greater in untreated epoxy composites than in treated composites.

The $\tan \delta$ peak of the more plasticized phase of epoxy composites aged in sea water at an elevated temperature is wide. This shows that a broad molecular weight chain network had built up in the epoxy structure when the degradation occurred. At room temperature, sustained load had no significance effect on the $\mathrm{Tg}$ of the samples for all aging conditions.

Open Access This article is distributed under the terms of the Creative Commons Attribution License which permits any use, distribution, and reproduction in any medium, provided the original author(s) and the source are credited.

\section{References}

1. Delor-Jestin F, Drouin D, Cheval P-Y, Lacoste J (2006) Thermal and photochemical ageing of epoxy resin e Influence of curing agents. Polym Degrad Stab 91:1247-1255

2. Yang Xiao-Wang, Shao-Rong Lu, Jiang Yu-Mei, Bo Zhang Jin-Hong Yu (2008) Preparation and curing kinetics investigation of diglycidyl ether of bisphenol A/liquid crystalline epoxy resin blends. Iran polymer 17(4):251-264

3. Alessi S, Conduruta D, Pitarresi G, Dispenza C, Spadaro G (2011) Accelerated ageing due to moisture absorption of thermally cured epoxy resin/polyethersulphone blends. Thermal, mechanical and morphological behavior. Polymer Degradation Stabilit 96:642-648

4. Blanco CG, Costa M, Recca A (2006) Development of an epoxy system characterised by low water absorption and high thermomechanical performances. J Appl Polymer Sci 100:4880

5. Pei Y, Wang K, Zhan M, Xu W, Ding X (2011) Thermal-oxidative aging of DGEBA/EPN/LMPA epoxy system: chemical structure and thermal mechanical properties. Polymer Degradation Stab 96:1179-1186

6. Kajorncheappunngam Somjai (1999) The effects of environmental aging on the durability of glass/ epoxy composites. Morgantown, West Virginia

7. Malajati Y, Therias S, Gardette J (2011) Influence of water on the photooxidation of KHJ phenoxy resins, 1 Mechanisms. Polymer Degrad Stab 96:144-150

8. Fan-Long Jin, Soo-Jin Park (2007) Improvement in fracture behaviours of epoxy resins toughened with sulfonated poly(ether sulphone). Polym Degrad Stab 92:509-514

9. Alperstein, D, Knani D, Goichman A, Narkis M (2012) Determination of plasticizers efficiency for nylon by molecular modeling. Polym Bull. doi:10.1007/s00289-012-0705-2

10. Mourad A-H, Abdel-Magid BM, El-Maaddawy T, Grami ME (2007) Effect of seawater and warm environment on glass/epoxy and glass/polyurethane composites. Appl Composite Mater 17:557-573

11. Ghaemy Musa, Riahi MohammadHossein (1996) Property - Structure Relationships in Epoxy Resin Systems. Iranian Polymer 5:1026-1265

12. Le Duigou A, Davies P, Baley C (2009) Seawater ageing of flax/poly(lactic acid) biocomposites. Polym Degrad Stab 94:1151-1162

13. Colombinia D, Martinez-Vega JJ, Merle G (2002) Dynamic mechanical investigations of the effects of water sorption and physical ageing on an epoxy resin system. Polymer 43:4479-4485

14. Sarathi R, Sahu RK, Rajeshkumar P (2007) Understanding the thermal, mechanical and electrical properties of epoxy nanocomposites. Mater Sci Eng, A 445-446:567-578

15. Mahdavian A, Sarrafi Y, Shabankareh M (2009) Nanocomposite particles with core-shell morphology III: preparation and characterization of nano Al2O3-poly(styrene-methyl methacrylate) particles via miniemulsion polymerization. Polym Bull 63:329-340

16. Roberts WO, Bergna HE (eds) (2006) Colloidal silica, fundamentals and applications. CRC Taylor and Francis, Boca Raton

17. Sipaut CS, Ahmad N, Adnan R, Ab I, Rahman MA, Dakar (2007) Preparation and characterization of bulk epoxy composites filled with modified fumed silica-epoxy nanocomposite. Appl Sci 7(1):27-34 
18. Abdolmaleki A, Mallakpour S, Borandeh S (2011) Effect of silane-modified $\mathrm{ZnO}$ on morphology and properties of bionanocomposites based on poly(ester-amide) containing tyrosine linkages. doi: 10.1007/s00289-011-0685-7

19. Rostami M, Mohseni M, Ranjbar Z (2011) Investigating the effect of $\mathrm{pH}$ on the surface chemistry of an amino silane treated nano silica. Pigm Resin Technol 40(6):363-373

20. Bezerra MA, Santelli RE, Oliveira EP, Villar LS, Escaleira LA (2008) Response surface methodology (RSM) as a tool for optimization in analytical chemistry. Talanta 76:965-977

21. Solouk A, Solati-Hashjinl M, Najarianl S, Mirzadeh H, Seifalian AM (2011) Optimization of acrylic acid grafting onto POSS-PCU nanocomposite using response surface methodology. Iranian Polymer 20:91-107

22. Dehghani K, Nekahi A, Mohammad Mirzaie MA (2010) Using response surface methodology to optimize the strain aging response of AA5052. Mater Sci Eng, A 527:7442-7451

23. Sarina, JZ, Zhang L (2012) Dynamic mechanical properties of Eucommia ulmoides gum with different degree of cross-linking. Polym Bull. doi:10.1007/s00289-012-0712-3

24. Wichmann MHG, Cascione M, Fiedler B, Quaresimin M, Schulte K (2006) Influence of particle surface treatment on mechanical behavior of fumed silica/ epoxy resin nano-composites. Compos Interfaces 13(8-9):699-715

25. Young RJ, Lovell PA (1991) Introduction to polymers, 2nd edn. Chapman and Hall Publisher, London

26. Lee JH, Rhee KY, Lee JH (2010) Effects of moisture absorption and surface modification using 3-aminopropyltriethoxysilane on the tensile and fracture characteristics of MWCNT/epoxy nanocomposites. Appl Surf Sci 256:7658-7667

27. Soulier JP, Barruet R, Chateauminois A, Chabert B, Gauthier R (1988) Interactions of fiber reinforced epoxy composites with different salt water solutions including isotonic liquid. Polym Commun 29:243-246

28. Kumar A, Commereuc S, Verney V (2008) Ageing of elastomers: a molecular approach based on rheological characterization. Polym Degrad Stab 85:751-757

29. Bohn MA, Cerri S (2010) Ageing behaviour of composite rocket propellant formulations investigated by DMA, SGA and GPC. Paper on the NDIA Insensitive Munitions \& Energetic Materials Technology Symposium (IMEMTS) on "International Progress in Insensitive Munitions and Energetic Materials", NDIA Event 1550, Session 9A, October 11-14, München, Germany

30. Dehghani K, Nekahi A, Mirzaie MAM (2011) Using response surface methodology to optimize the strain aging response of AA5052. Mater Sci Eng, A 527:7442-7451 